\title{
Mitigating the Adverse Impact of Un-Deterministic Distributed Generation on a Distribution System Considering Voltage Profile
}

\author{
Muhammad Aamir Aman \\ Electrical Engineering \\ Department \\ IQRA National University \\ Peshawar, Pakistan
}

\author{
Sanaullah Ahmad \\ Electrical Engineering \\ Department \\ IQRA National University \\ Peshawar, Pakistan
}

\author{
Babar Noor \\ Electrical Engineering \\ Department \\ IQRA National University \\ Peshawar, Pakistan
}

\author{
Fazal Wahab Karam \\ Electrical Engineering \\ Department, COMSATS \\ University, Abbottabad, \\ Pakistan
}

\begin{abstract}
Electric power systems are enforced to operate near to their stability limit due to the fast increase in power demand. Therefore, voltage stability has become a primary concern. The main cause of voltage variations is the imbalance between generation and consumption. In order to mitigate variations in voltage profile, most of the modern electric power systems are adopting new emerging technologies such as distributed generation (DG). Validation of standard voltage optimization is a difficult task when DG is integrated to medium and low voltage networks. Integration of DG will have diverse impacts on voltage levels when connected un-deterministically to the electric distribution system. This paper analyzes both the impacts of undeterministic large and small size DG on voltage profile. Feasible solutions by incorporating reactors and increasing cross sectional area of cables, variation in voltage profile were mitigated. Detailed simulations were performed in ETAP by modeling and evaluating Kohat road grid station situated in Peshawar, Pakistan. The results anticipated that this approach can be useful to ensure standard voltage profile and better utilization of undeterministic DG units.
\end{abstract}

Keywords-electric power system; distributed generation; voltage profile; synchronous; induction; generator

\section{INTRODUCTION}

As energy demand increases, the complexity of power system networks also rises [1]. Distributed generation (DG) is steadily becoming a viable option. DG is generation at distribution level which can be classified into two major groups, renewable (non-conventional) and non-renewable (conventional) energy sources [2]. Voltage control equipment in the distribution network mostly considers unidirectional power flow, from the transmission network to step down substations and then to the low voltage distribution network. Voltage may drop from the standard level due to different factors like line losses or line impedances. Injecting DG on the distribution system may have a significant impact on power flow, voltage profile, and fault current levels. Voltage is increased due to the power generated by DG injected in the distribution system, which may cause variation in the voltage profile [3]. By injecting DG, power flow becomes bidirectional. The impact depends upon the placement and size of the DG unit. Power system operation might be harmfully affected by installing a DG unit, if definite least possible values for control, injection and location are not retained. For positive impacts, DG must be appropriately synchronized with the operational system and feeder scheme. Integration of DG and its impact on the system is relative to feeder demand and capacity therefore the coordination of DG with the system must be optimized to avoid these issues [4]. This study demonstrates the impact of distribution system components on voltage profile violation caused by DG integration. This study is validated through ETAP. Six busbar distribution systems are selected as test cases, which are modeled and analyzed in ETAP. Two cases are formulated using un-deterministic small and large size DG units. Firstly, cross sectional area of conductors is increased and voltage profile is evaluated, considering the injection of a small size DG unit. Secondly, reactors are installed to analyze its effect on voltage profile considering a large size DG unit.

\section{DG IMPACT ON DISTRIBUTION SYSTEM}

DG supports voltage rise at the termination of the feeder. Though, where the DG is introduced, it may raise the voltage above the standard limits. Voltage may be greater at the consumer amenities than on the primary side of the distribution transformer and may even go above the voltage higher limits. This means that both high and low service voltage can take place due to the mismatch of DG with the radial power stream. An unacceptable voltage profile is produced, when a small extent of DG power is connected at the wrong location, while a very huge quantity of DG power permits satisfactory operative conditions. So, for better voltage profile DG units must be placed at the optimal location. Injection of DG may cause negative impacts on the system e.g. voltage rise issues. The nondeterministic or probabilistic DGs are installed at the client's location. Their parameters such as optimal location, size, and type are not known. Injecting a huge amount of undeterministic DGs to the system causes problems regarding voltage rise issues. Erratic operation may cause too wide voltage variation. This variation is undesirable and must be kept within the prescribed limits (i.e. declared voltage $\pm 6 \%$ ).Voltage regulating equipment is installed at different locations to achieve this limit. Different solution methods are 
proposed by various researchers. There is a huge amount of elements between a power plant and customers' premises. Voltage control equipment's are used for two reasons at more than one location in the system. The first reason is that in the transmission and distribution system there is a significant voltage drop due to the widespread power network and the second reason is the divergent load characteristics of the numerous circuits of the power system. This voltage control equipment may be installed with generators in series, or with each feeder in series or even with bus bars. In this research work, reactors are installed at different locations to minimize voltage rise problems. Reactors are used to limit the voltage level by adding additional reactance to the system. Compared to ohmic resistance, these reactors are designed with a coil with large inductance. The reactor's winding must be solidly braced. System efficiency is changed in a very small amount if a small reactor resistance is added to the system.

Inclusion of DG can impact the system voltage profile. Injection of DG can improve the voltage where the voltage dip and blackout are of concern for service providers. However DG may complicate the equipment used for regulation and deviate the voltage above or below acceptable limits. In this paper, DG is injected on a radial distribution system and its impact is analyzed. The DG unit is injected on locations where the voltage profile is not that good. Researchers showed that inappropriate selection of DG size and location may have adverse impact on the system [5]. DG location and load parameters affect greatly the voltage profile of the system. When DG is operated in voltage control mode the feeder reactance is negligible [6]. It is necessary for utilities to choose an optimum location for DG injection so that the voltage profile will be improved and system losses will reduce [7].

\section{MATHEMATICAL MODELING AND THE NEWTON- RAPHSON METHOD}

Steady state analysis is used for power systems because of their slowly operating changing nature. Transients occurred from disruption are assumed in the steady state as unchanging. The operation tool for the steady state analysis is known as power flow analysis. In load flow analysis the voltage magnitude and phase angle, flow of active and reactive power throughout the network at all buses can be find. Different techniques are used for solving the power flow equations, Newton-Raphson method is discussed below. Taylor's series expansion for a function of two or more variables is the basis for the Newton-Raphson method for solving load flow problems. The method begins the problem's solution involving only two equations and two variables. Then the extension of the analysis to the solution of load flow equation will be discussed. Let us consider the equation of a function of two variables, $Z_{1}$ and $Z_{2}$ equal to a constant $C_{1}$ as

$$
\mathrm{F}_{1}\left(\mathrm{Z}_{1}, \mathrm{Z}_{2}\right)=\mathrm{C}_{1}
$$

Similarly the second equation becomes

$$
\mathrm{F}_{2}\left(\mathrm{Z}_{1}, \mathrm{Z}_{2}\right)=\mathrm{C}_{2}
$$

Initially estimates of the solution of these equations is $Z_{1}{ }^{(0)}$ and $Z_{2}{ }^{(0)}$. The corrections $\Delta Z_{1}{ }^{(0)}$ and $\Delta Z_{2}{ }^{(0)}$ must be added to $\mathrm{Z}_{1}{ }^{(0)}$ and $\mathrm{Z}_{2}{ }^{(0)}$ for the correct solution.

$$
\begin{aligned}
& \mathrm{C}_{1}=\mathrm{F}_{1}\left(\mathrm{Z}_{1}, \mathrm{Z}_{2}\right)=\mathrm{F}_{1}\left(\mathrm{Z}_{1}{ }^{(0)}+\Delta \mathrm{Z}_{1}{ }^{(0)}, \mathrm{Z}_{2}+\Delta Z_{2}{ }^{(0)}\right) \\
& \mathrm{C}_{2}=\mathrm{F}_{2}\left(\mathrm{Z}_{1}, \mathrm{Z}_{2}\right)=\mathrm{F}_{2}\left(\mathrm{Z}_{1}{ }^{(0)}+\Delta Z_{1}{ }^{(0)}, \mathrm{Z}_{2}+\Delta \mathrm{Z}_{2}{ }^{(0)}\right)
\end{aligned}
$$

Now the problem is to find $\Delta Z_{1}{ }^{(0)}$ and $\Delta Z_{2}{ }^{(0)}$. Expanding (3) and (4) in Taylor's series we get:

$\mathrm{C}_{1}=\mathrm{F}_{1}\left(\mathrm{Z}_{1}{ }^{(0)}, \mathrm{Z}_{2}{ }^{(0)}\right)+\left.\Delta Z_{1}{ }^{(0)} \frac{\partial F_{1}}{\partial Z_{1}}\right|^{(0)}+\left.\Delta Z_{2}{ }^{(0)} \frac{\partial F_{1}}{\partial Z_{2}}\right|^{(0)}+\cdots(5)$
$\mathrm{C}_{2}=\mathrm{F}_{2}\left(\mathrm{Z}_{1}{ }^{(0)}, \mathrm{Z}_{2}{ }^{(0)}\right)+\left.\Delta Z_{1}{ }^{(0)} \frac{\partial F_{2}}{\partial Z_{1}}\right|^{(0)}+\left.\Delta Z_{2}{ }^{(0)} \frac{\partial F_{2}}{\partial Z_{2}}\right|^{(0)}+\cdots(6)$

Partial derivatives of order greater than one will be neglected. So, writing (5) and (6) in matrix form will become:

$$
\left[\begin{array}{c}
C_{1}-F_{1}\left(Z_{1}{ }^{(0)}, Z_{2}{ }^{(0)}\right) \\
C_{2}-F_{2}\left(Z_{1}{ }^{(0)}, Z_{2}{ }^{(0)}\right)
\end{array}\right]=\left[\begin{array}{ll}
\frac{\partial F_{1}}{\partial Z_{1}} & \frac{\partial F_{1}}{\partial Z_{2}} \\
\frac{\partial F_{2}}{\partial Z_{2}} & \frac{\partial F_{2}}{\partial Z_{2}}
\end{array}\right]\left[\begin{array}{c}
\Delta Z_{1}{ }^{(0)} \\
\Delta Z_{2}{ }^{(0)}
\end{array}\right]
$$

Where partial derivatives of the square matrix are known as Jacobian " $\mathrm{J}$ " or $\mathrm{J}^{(0)}$ in this case. $\mathrm{F}_{1}\left(\mathrm{Z}_{1}^{(0)}, \mathrm{Z}_{2}^{(0)}\right)$ is the calculated value of $\mathrm{k} 1$ for the estimated values of $Z_{1}{ }^{(0)}$ and $Z_{2}{ }^{(0)}$. If $\Delta C_{1}{ }^{(0)}$ is selected as the specified value of $\mathrm{C}_{1}$ minus the calculated value of $\mathrm{C}_{1}$ and also for $\Delta \mathrm{C}_{2}{ }^{(0)}$.

$$
\left[\begin{array}{l}
\Delta C_{1}{ }^{(0)} \\
\Delta C_{2}{ }^{(0)}
\end{array}\right]=\mathrm{J}^{(0)}\left[\begin{array}{l}
\Delta Z_{1}{ }^{(0)} \\
\Delta Z_{2}{ }^{(0)}
\end{array}\right]
$$

For a total of $\mathrm{N}$ buses the calculated voltage at any bus $\mathrm{A}$ where $\mathrm{P}_{\mathrm{A}}$ and $\mathrm{Q}_{\mathrm{A}}$ are given as:

$$
\mathrm{V}_{\mathrm{A}}=\frac{1}{Y_{A A}}\left[\frac{P_{A}-\mathrm{j} Q_{A}}{V_{A}{ }^{*}}-\sum_{n=1}^{N} Y_{A n} V_{n}\right]
$$

is obtained from the following equation:

$$
\mathrm{P}_{\mathrm{A}}-\mathrm{jQ} \mathrm{Q}_{\mathrm{A}}=\left(Y_{A A} V_{A}+\sum_{n=1}^{N} Y_{A n} V_{n}\right) \mathrm{V}_{\mathrm{A}}^{*}
$$

where $n \neq A$. If $n$ is permitted to equals to $A$,

$$
\begin{aligned}
& \mathrm{P}_{\mathrm{A}}-\mathrm{jQ} \mathrm{Q}_{\mathrm{A}}=\mathrm{V}_{\mathrm{A}}^{*} \sum_{n=1}^{N} Y_{A n} V_{n} \\
& \mathrm{P}_{\mathrm{A}}=\mathrm{V}_{\mathrm{A}}^{*} \sum_{n=1}^{N} Y_{A n} V_{n} \\
& \mathrm{Q}_{\mathrm{A}}=-\operatorname{Img}\left\{\mathrm{V}_{\mathrm{A}}^{*} \sum_{n=1}^{N} Y_{A n} V_{n}\right\}
\end{aligned}
$$

Equation (13) evaluates reactive power $\mathrm{Q}_{\mathrm{A}}$ for the better previous voltage values at the buses. $\mathrm{Q}_{\mathrm{A}}$ is substituting in (10) to get a new $\mathrm{Y}_{\mathrm{A}}$. Voltage at bus and line admittances in polar form is:

$\mathrm{V}_{\mathrm{A}}=\left|\mathrm{V}_{\mathrm{A}}\right|<\delta_{A} ; \mathrm{V}_{\mathrm{n}}=\left|\mathrm{V}_{\mathrm{n}}\right|<\delta_{n} ; Y_{A n}=|\mathrm{Ykn}|<\theta_{A n}$

By substituting these in (11) we get:

$$
\begin{aligned}
& \mathrm{P}_{\mathrm{A}}-\mathrm{jQ} \mathrm{Q}_{\mathrm{A}}=\sum_{n=1}^{N} Y_{A n} V_{n}<\theta_{A n}+\delta_{n}-\delta_{A} \\
& \mathrm{P}_{\mathrm{A}}=\sum_{n=1}^{N} Y_{A n} V_{n} \operatorname{Cos}\left(\theta_{A n}+\delta_{n}-\delta_{A}\right)
\end{aligned}
$$

and

$$
\mathrm{Q}_{\mathrm{A}}=-\sum_{n=1}^{N} Y_{A n} V_{n} \operatorname{Sin}\left(\theta_{A n}+\delta_{n}-\delta_{A}\right)
$$

Now, by comparing (8) with the power system,

$$
\begin{aligned}
& \Delta C_{1}{ }^{(0)}=\Delta P_{A}=P_{\text {ASpec }}-P_{\text {ACalc }} \\
& \Delta C_{2}{ }^{(0)}=\Delta Q_{A}=Q_{\text {ASpec }}-Q_{\text {ACalc }}
\end{aligned}
$$


$\Delta Z_{1}^{(0)}=\Delta \delta_{A}^{(0)}$

$\Delta Z_{2}^{(0)}=\left|V_{A}^{(0)}\right|$

The Jacobian "J" contains the partial derivative of real and reactive power. The basic iterative procedure is as follows:

- Begin with the preceding case result.

- Calculate the divergence and end it where the bound of acceptance value outstrips.

- Power flow calculation for the Jacobian, update value and return to step II.

\section{ANALYSIS OF TEST FEEDER CIRCUIT}

An $11 \mathrm{KV}$ residential radial distribution feeder located at Kohat Road Peshawar, Khyber Pakhtunkhwa, Pakistan is considered for analysis. Electrical transient analyzer program (ETAP) is used for analysis of the selected radial distribution feeder. ETAP is user friendly, and has the capability to perform analysis related to distribution generation. This $11 \mathrm{kV}$ radial feeder is energized from a bus bar of $132 \mathrm{kV}$ with the help of a 31.5/40 MVA transformer. The source for this radial feeder is the $132 \mathrm{kV}$ bus bar and is shown as power grid with a short circuit capacity of 2100 MVA. The base for these calculated data is 100 MVA. Seven distribution transformers are connected to seven different sizes of lumped loads with a lagging power factor of 0.85 in this radial feeder. For interconnection of buses with each other, cables are used. The type of cable used in this system is 3-phase overhead aluminum conductor having insulation of cross-linked polyethylene. The length for each conductor is taken as $500 \mathrm{~m}$ with a cable class percentage of $100 \%$.

\section{MODELING OF DISTRIBUTED GENERATION UNITS}

Synchronous and induction generators are used as DG units in this research paper. These units will be operated and analyzed under different conditions. To analyze the effect of DG unit on the radial distribution system, different unit types have been placed at different locations.

\section{A. Without DG Unit}

In this case the system analysis will be conducted without DG injection to the system. This analysis will act as a reference case for the other cases. The impact of DG on residential distribution system will be studied.

\section{B. Injecting a Small Amount of Un-Deterministic DG Units.}

In this case a small amount of DG units will be injected in the system and its impact will be analyzed. For improvement of system voltage profile the cross-sectional area (CSA) of the conductors will vary and its impact on the system will be analyzed. By increasing CSA of the conductor the resistance of the conductor decreases and hence the voltage profile will improve at the bus bars. This case consists of two situations, the worst situation is taken first i.e. by injecting small undeterministic DG units and no change in the conductor's CSA and existing CSA $\mathrm{mm}^{2}$ are taken. In the second case, the CSA of the conductors has been upgraded by increasing the size of the cross-sectional area.

\section{Injecting A Huge Amount of Un-Deterministic DG Units.}

By injecting a huge amount of un-deterministic DG units to the distribution system, the impact on voltage profile will be analyzed. In this case reactors are used for the improvement of voltage profile. Reactors are designed as coils with high inductance.

\section{TEST CASES}

A. Case-I

The results of load flow analysis of the radial distribution network in case-I are shown in Figure 1. No DG unit is injected to the system. As mentioned above, this case is taken as a reference for the other cases.

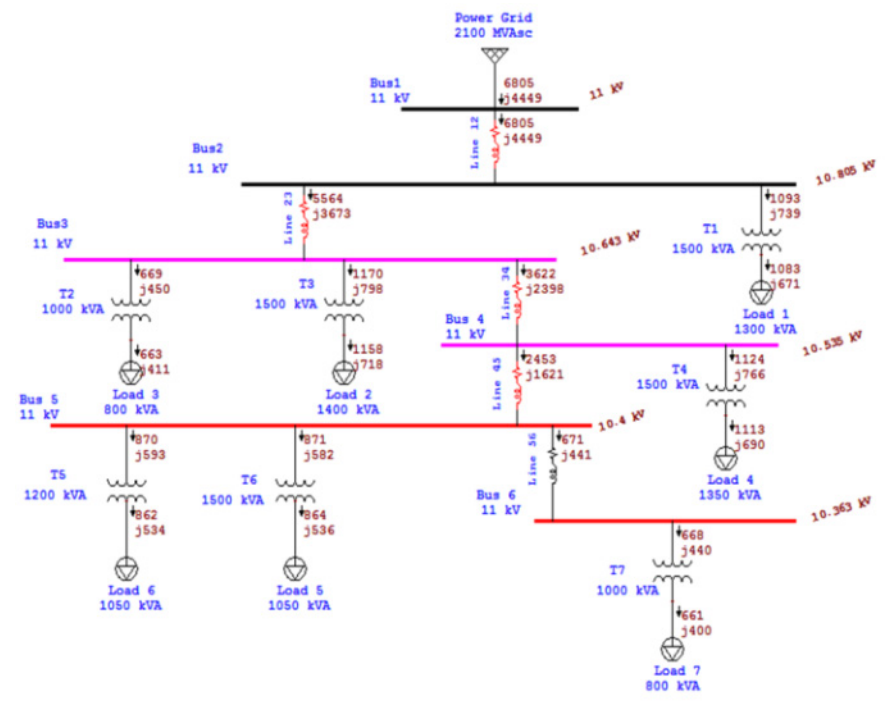

Fig. 1. With no DG unit injection to the system.

\section{B. Case-II}

In this case a small DG unit will be injected in the system and its impact will be analyzed. When a small DG unit is injected in the system there is no change in the voltage profile, so for the betterment of voltage profile the size of the conductor CSA is increased. Two situations are taken in this case: at first the worst situation is taken i.e. by injecting the small DG unit in the existing system with no change in the conductor CSA while in the second case the size of the CSA will be upgraded by increasing the size of cross-sectional area of the conductor. In the following manner the voltage profile will be analyzed.

1) Injecting a small amount of Un-deterministic DG units and keeping existing CSA mm2 for the radial distribution system

In this situation the DG unit is injected in the existing system with no change in the size of the CSA of the conductors used in the radial distribution system. The load flow analysis results for the first situation of case-II are shown in Figure 2. The load requirement is fulfilled by the power grid and undeterministic DG. This is taken as reference for the second situation. Real time condition and voltage levels at different 
bus bars are shown in Figure 2. In Table I the drops in voltage from one bus to another are shown as percentages.

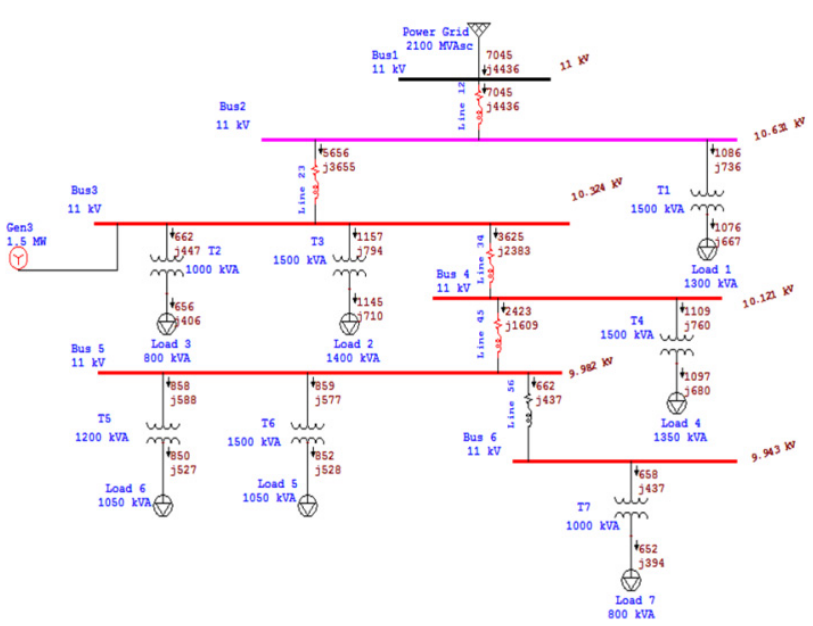

Fig. 2. Injecting DG without change in the cross-sectional area of the conductors.

TABLE I. CASE-II: BUS VOLTAGE IN PERCENTAGE OF THE SYSTEM WITH EXISTING CSA

\begin{tabular}{|c|c|c|}
\hline \multirow{2}{*}{ Branch/ Circuit ID } & \multicolumn{2}{|c|}{ \% Bus Voltage } \\
\cline { 2 - 3 } & From & To \\
\hline Line 12 & 100.0 & 96.6 \\
\hline Line 23 & 96.6 & 93.9 \\
\hline T1 & 96.6 & 93.3 \\
\hline Line 34 & 93.9 & 92.0 \\
\hline T2 & 93.9 & 90.6 \\
\hline T3 & 93.9 & 90.1 \\
\hline Line 45 & 92.0 & 90.7 \\
\hline T4 & 92.0 & 88.3 \\
\hline Line 56 & 90.7 & 90.4 \\
\hline T5 & 90.7 & 87.2 \\
\hline T6 & 90.7 & 87.9 \\
\hline T7 & 90.4 & 87.1 \\
\hline
\end{tabular}

\section{2) Upgrading CSA}

In this situation the system has been upgraded by increasing the size of the CSA of the conductors. The CSA is taken as $185 \mathrm{~mm}^{2}$ for the conductors used in the radial distribution system. The load flow analysis results are shown in Figure 3. The load requirement is fulfilled by the power grid and the undeterministic DG unit. Real time condition and levels of voltage at different bus bars are shown. Comparing voltages from the first situation, voltage profile is much better and clear improvement can be seen. In Table II the drop in voltage from one bus to another are shown. Voltage profile is much better and clear improvement can be seen.

\section{Case-III}

In this case, a huge amount of un-deterministic DGs is injected in the radial distribution network and its impact on the system is analyzed. Two situations are taken in this case, in first the un-deterministic DGs are installed at Busbar-3. This is recognized as the worst situation because it would produce voltage profile problem. In the second situation the rectors are connected across the Busbar 2, 3 and across the transformer secondary and busbar3.

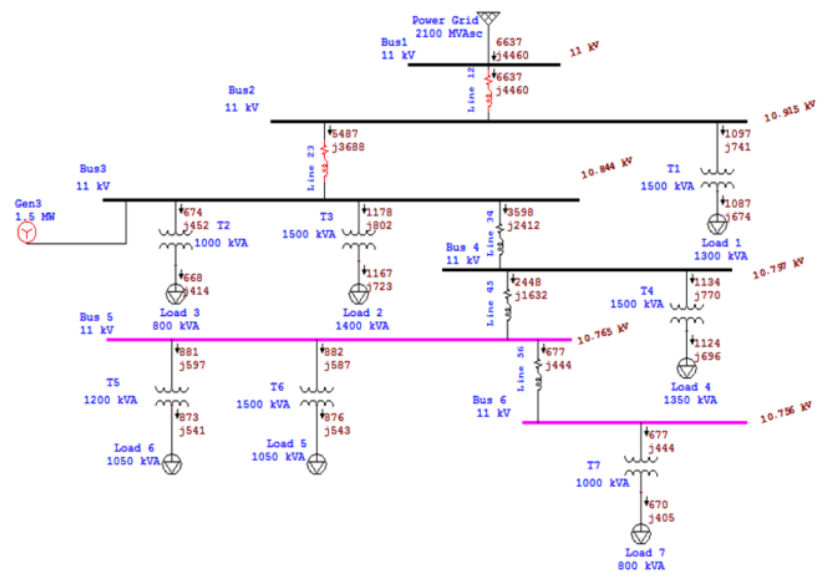

Fig. 3. Cross-sectional area of the conductors are upgraded.

TABLE II. CASE-II: BUS VOLTAGE IN PERCENTAGE OF THE SYSTEM WHEN UPGRADING EXISTING CSA

\begin{tabular}{|c|c|c|}
\hline \multirow{2}{*}{ Branch/ Circuit ID } & \multicolumn{2}{|c|}{ \% Bus Voltage } \\
\cline { 2 - 3 } & From & To \\
\hline Line 12 & 100.0 & 99.2 \\
\hline Line 23 & 99.2 & 98.6 \\
\hline T1 & 99.2 & 95.9 \\
\hline Line 34 & 98.6 & 98.2 \\
\hline T2 & 98.6 & 95.4 \\
\hline T3 & 98.6 & 95.0 \\
\hline Line 45 & 98.2 & 97.9 \\
\hline T4 & 98.2 & 94.7 \\
\hline Line 56 & 97.9 & 97.8 \\
\hline T5 & 97.9 & 94.5 \\
\hline T6 & 97.9 & 95.2 \\
\hline T7 & 97.8 & 94.7 \\
\hline
\end{tabular}

\section{1) By injecting $s$ huge amount of un-deterministic DGs at} Busbar-3

Under this operating strategy the maximum DG output coincides with minimum load condition. This case is taken for the purpose that what will happen if consumers are freely allowed to install DGs on their premises. The load flow analysis results are shown in Figure 4. Real time condition and levels of voltage at different bus bars are shown. In Table III the drops in voltage from one bus to another are shown in percentage.

\section{2) Installing reactors to improve voltage profile}

The voltage profile is improved by installing reactors. Reactors may be connected in series with the generators, in series with each feeder and in bus-bars depending on the requirement of the system. Two reactors are placed here, the first one is connected in series with the secondary of the transformer and the second one is connected in series with Line 23. The load flow analysis results are shown in Figure 5. The voltage level at different bus bars is shown. The voltage profile 
is much better and clear improvement can be seen. In Table IV the drops in voltage from one bus to another are shown.

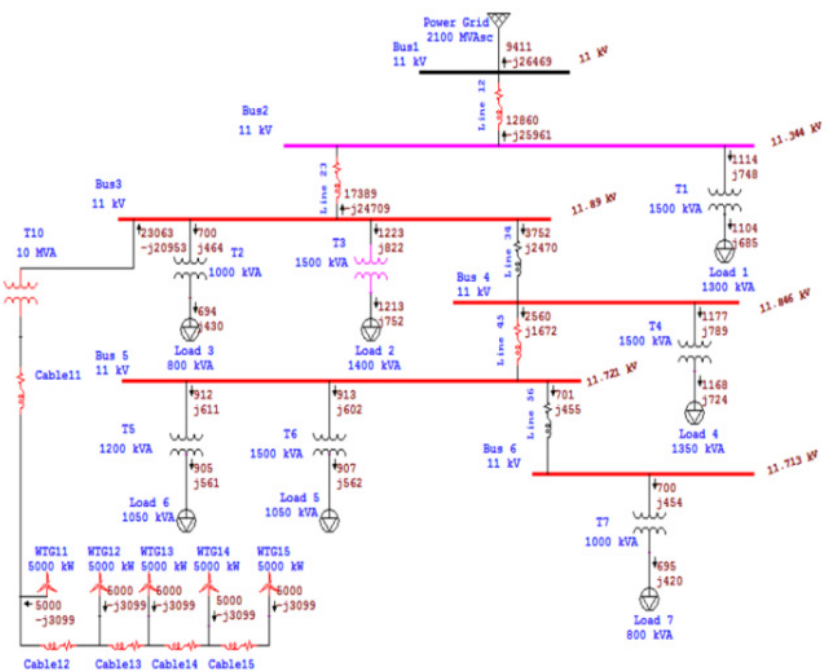

Fig. 4. Installing un-deterministic DGs at Busbar-3.

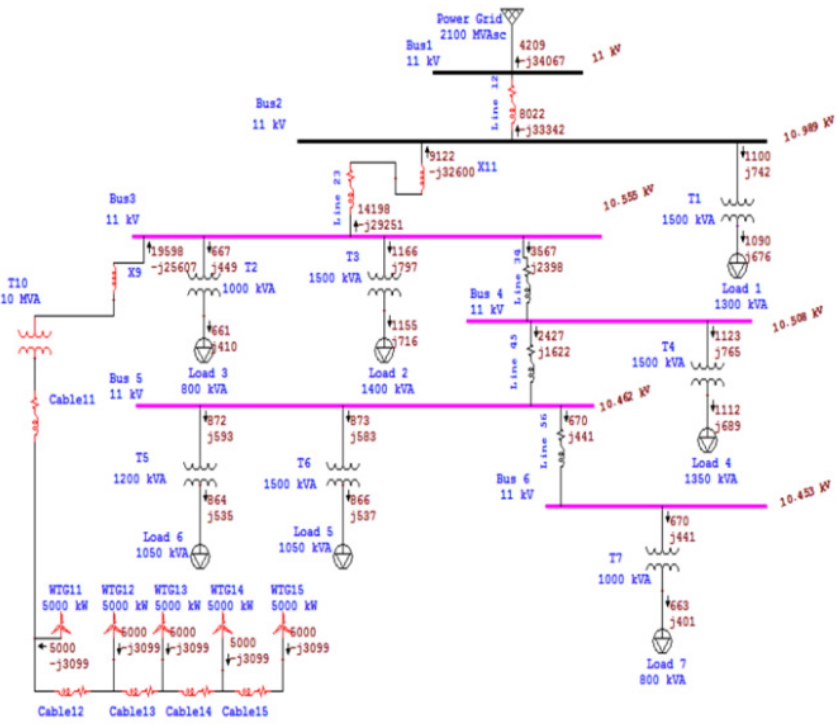

Fig. 5. Installing reactors for voltage improvement.

\section{RESULTS AND DISCUSSION}

In Table $\mathrm{V}$ the real and reactive power, injected by the grid and DG units, is shown.

\section{A. Voltage Profile Analysis}

When different types of DG units are injected to the system they cause different impact on voltage profile.

\section{1) Case-I}

No DG unit is injected in this case. There is clear decrease in voltage profile from source to load as shown in Figure 6. The voltage level is decreased due to line impedance.
TABLE III. CASE-III: BUS VOLTAGE IN PERCENTAGE OF THE SYSTEM BY INJECTING HUGE AMOUNT OF UN-DETERMINISTIC DG UNITS

\begin{tabular}{|c|c|c|}
\hline \multirow{2}{*}{ Branch/ Circuit ID } & \multicolumn{2}{|c|}{ \% Bus Voltage } \\
\cline { 2 - 3 } & From & To \\
\hline Line 12 & 100.0 & 103.1 \\
\hline Line 23 & 103.1 & 108.1 \\
\hline T1 & 103.1 & 99.9 \\
\hline Line 34 & 108.1 & 107.7 \\
\hline T2 & 108.1 & 105.1 \\
\hline T3 & 108.1 & 104.7 \\
\hline T10 & 108.1 & 99.4 \\
\hline Line 45 & 107.7 & 106.6 \\
\hline T4 & 107.7 & 104.4 \\
\hline Line 56 & 106.6 & 106.5 \\
\hline T5 & 106.6 & 103.4 \\
\hline T6 & 106.6 & 104.0 \\
\hline T7 & 105.5 & 103.5 \\
\hline Cable11 & 99.4 & 100.6 \\
\hline Cable12 & 100.6 & 101.5 \\
\hline Cable13 & 101.5 & 102.3 \\
\hline Cable14 & 102.3 & 102.8 \\
\hline Cable15 & 102.8 & 103.0 \\
\hline & \multicolumn{2}{|}{}
\end{tabular}

TABLE IV. CASE-III BUS VOLTAGE BY INJECTING HUGE AMOUNT OF UNDETERMINISTIC DG UNITS

\begin{tabular}{|c|c|c|}
\hline \multirow{2}{*}{ Branch/ Circuit ID } & \multicolumn{2}{|c|}{$\%$ Bus Voltage } \\
\hline & From & To \\
\hline Line 12 & 100.0 & 99.9 \\
\hline Line 23 & 96.0 & 92.6 \\
\hline T1 & 99.9 & 96.6 \\
\hline $\mathrm{X} 11$ & 99.9 & 92.6 \\
\hline Line 34 & 96.0 & 95.5 \\
\hline T2 & 96.0 & 92.8 \\
\hline $\mathrm{T} 3$ & 96.0 & 92.3 \\
\hline $\mathrm{X9}$ & 96.0 & 90.1 \\
\hline Line 45 & 95.5 & 95.1 \\
\hline T4 & 95.5 & 92.0 \\
\hline Line 56 & 95.1 & 95.0 \\
\hline T5 & 95.1 & 91.6 \\
\hline T6 & 95.1 & 92.4 \\
\hline T7 & 95.0 & 91.8 \\
\hline Cable11 & 78.4 & 85.8 \\
\hline T10 & 78.4 & 90.1 \\
\hline Cable12 & 85.8 & 86.9 \\
\hline Cable13 & 86.9 & 87.8 \\
\hline Cable14 & 87.8 & 88.4 \\
\hline Cable15 & 88.4 & 88.6 \\
\hline
\end{tabular}

TABLE V. INJECTION OF REAL AND REACTIVE POWER FROM DG UNITS AND GRID

\begin{tabular}{|c|c|c|c|c|c|}
\hline \multirow{2}{*}{ Case } & \multirow{2}{*}{ Situations } & \multicolumn{2}{|c|}{$\begin{array}{c}\text { DG } \\
\text { Injected Power }\end{array}$} & \multicolumn{2}{c|}{$\begin{array}{c}\text { Grid } \\
\text { Injected Power }\end{array}$} \\
\cline { 3 - 6 } & & MW & MVAR & MW & MVAR \\
\hline 1 & 1 & 0 & 0 & 6.805 & 4.449 \\
\hline 2 & 1 & 1.5 & 0 & 7.045 & 4.436 \\
\hline 2 & 1 & 1.5 & 0 & 6.637 & 4.460 \\
\hline 3 & 2 & 25 & -15.5 & -9.411 & 26.469 \\
\hline 3 & 2 & 25 & -15.5 & -4.209 & 34.057 \\
\hline
\end{tabular}

2) Case-II

In this case the small size un-deterministic DG unit is injected with no change in the size of the CSA of the conductors used in radial distribution system in first situation, and in second situation the size of the CSA of the conductor is increased. By increasing CSA the resistance of the conductor is 
decreased and hence we get better results by improving voltage profile. The result obtained from both situations is shown in Figure 7. The up gradation of CSA shows the best voltage profile.

\section{3) Case-III}

In this case a large amount of un-deterministic DG units is injected in the system. By doing so, the voltage level raises or sometimes it reduces below standards. In this case the voltage raises above the limit. Reactors are used to level down the voltage profile. Both results before and after the reactors installation are shown in Figure 8. When reactors are installed the voltage profile is improved.

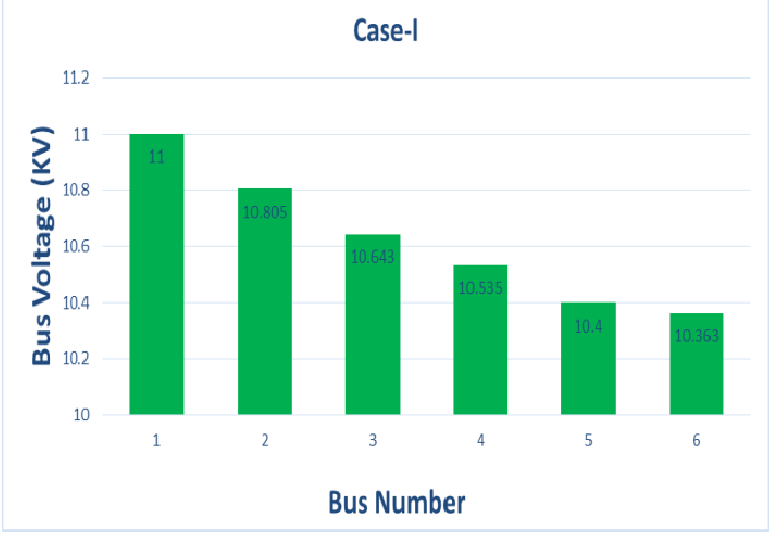

Fig. 6. Radial feeder voltage arrangement.

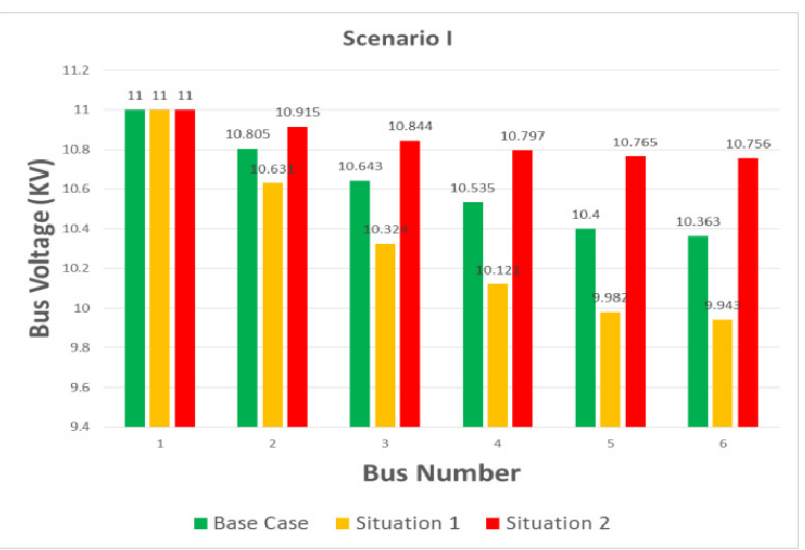

Fig. 7. Impacts of voltage profile by injecting Un-deterministic DG unit and increasing CSA of conductor.

\section{CONCLUSION AND FUTURE WORK}

Voltage stability is a prime utility responsibility. DG may increase or decrease the voltage level from standard limit depending upon the nature, size and placement of the DG unit. After injecting un-deterministic DG units to the distribution system and analyzing different cases, in this research work it is concluded that by increasing the CSA of distribution cables the voltage level can be improved to standard voltage while introducing reactors can decrease the voltage level to standard voltage. CSAs of distribution cable are increased when the injection of DG units doesn't affect the voltage profile while reactors are introduced when DG units increase the voltage level above the standard. In future, the impacts of different conventional and also un-conventional DG units can be analyzed considering harmonics and reliability.

\section{ACKNOWLEDGMENT}

Authors gratefully express their thanks to the Electrical Engineering Department of Iqra National University, Pakistan for their assistance and support.

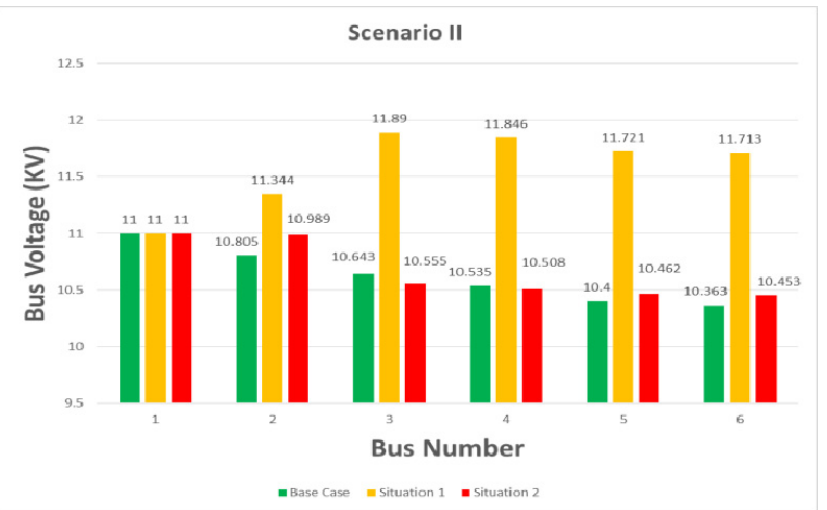

Fig. 8. Impact on voltage profile by injecting un-deterministic DG units and installing reactors.

\section{REFERENCES}

[1] M. O. Alruwaili, M. Y. Vaziri, S. Vadhva, S. Vaziri, "Impact of distributed generation on voltage profile of radial power systems", 2013 IEEE Green Technologies Conference, Denver, USA, pp. 473-480, IEEE, 2013

[2] P. C. Chen, R. Salcedo, Q. Zhu, F. De Leon, D. Czarkowski, Z. P. Jiang, R. E. Uosef, "Analysis of voltage profile problems due to the penetration of distributed generation in low-voltage secondary distribution networks", IEEE Transactions on Power Delivery, Vol. 27, No. 4, pp. 2020-2028, 2012

[3] D. Caples, S. Boljevic, M. F. Conlon, "Impact of distributed generation on voltage profile in $38 \mathrm{kV}$ distribution system", 2011 8th International Conference on the European Energy Market, Zagreb, Croatia, pp. 532536, IEEE, 2011

[4] Q. Sun, Z. Li, H. Zhang, "Impact of distributed generation on voltage profile in distribution system", International Joint Conference on Computational Sciences and Optimization, (CSO 2009), Sanya, Hainan, China, pp. 249-252, IEEE, 2009

[5] V. Van Thong, J. Driesen, R. Belmans, "Interconnection of Distributed Generators and Their Influences on Power Sytem", International Energy Journal Vol. 6, No. 1 Part 3, PP. 3-127-3-140, 2005

[6] L. Ramesh, S. P. Chowdhury, S. Chowdhury, A. A. Natarajan, C. T. Gaunt, "Minimization of Power Loss in Distribution Networks by Different Techniques", International Journal of Electrical Computer Engineering, Vol. 3, No. 4, pp.661-667, 2009

[7] M. Aamir Aman, S. Ahmad, A. ul Asar, B. Noor, "Analyzing the diverse impacts of conventional distributed energy resources on distribution system", International Journal of Advanced Computer Science and Applications, Vol. 8, No. 10, pp. 390-396, 2017 